\title{
Effect of disulfide and sulfhydryl reagents on abortive and productive elongation catalyzed by Escherichia coli RNA polymerase
}

\author{
Marek Radłowski ${ }^{1}$ and Dominique $\mathrm{Job}^{2}$ \\ ${ }^{1}$ Institute of Plant Genetics, Polish Academy of Sciences, Strzeszyniska 34, 60-479 Poznań, Poland \\ ${ }^{2}$ Unite Mixte (UM41) Rhône-Poulenc associée au Centre National de la Recherche Scientifique, \\ Rhône-Poulenc Agrochimie, 14-20 rue Pierre Baizet, 69263 Lyon Cedex 9, France
}

Received: 23 April, 1994

Key words: RNA polymerase, abortive elongation, sulfhydryl reagents

\begin{abstract}
The effect of disulfide and sulfhydryl reagents on the rate of abortive and productive elongation has been studied using Escherichia coli RNA polymerase holoenzyme and poly[d(A-T)] as template. In the presence of UTP as a single substrate and UpA as a primer, the enzyme catalyzed efficiently the synthesis of the trinucleotide product UpApU. Incubation of RNA polymerase with $1 \mathrm{mM}$ 2-mercaptoethanol resulted in a 5-fold increase of the rate of UpApU synthesis. In contrast, incubation of the enzyme with 1 mM 5,5'-dithio-bis(2-nitrobenzoic) acid resulted in a 6-fold decrease of the rate of abortive elongation. Determination of the steady state kinetic constants associated with UpApU synthesis disclosed that the disulfide and sulfhydryl reagents mainly affected the rate of UpApU release from the ternary transcription complexes and therefore influenced the stability of such complexes.
\end{abstract}

Incorporation of nucleotides into RNA chains results in conversion of a DNA-RNA binary complex into a more stable ternary transcription complex, RNA polymerase-DNA-RNA (reviewed by von Hippel et al. [1]). In prokaryotes the DNA-dependent RNA polymerase (EC 2.7.7.6) exists under two forms. The core enzyme contains four polypeptide chains, $\beta, \beta^{\prime}$ and $\alpha_{2}$, and catalyzes with a high processivity the elongation of RNA chains. The holoenzyme is formed by association of the core enzyme with sigma factor, and is involved in the initiation phase of the polymerization reaction. With Escherichia coli RNA polymerase the number of extension steps required to reach a stable state of the ternary transcription complex depends on the nature of the DNA template and on the strength of the promoter site where initiation of RNA synthesis occurs. Thus, during the initial phase of polymerization, oligomers up to 8-10 nucleotides long might be produced abortively [2]. At the end of the abortive phase, sigma factor is released and the resulting core enzyme enters in the elongation phase of transcription [2-5].

- Synthetic copolymers such as poly[d(A-T)] and complementary dinucleotide primers such as UpA or ApU proved extremely useful in characterization of enzymological aspects of the abortive elongation phenomenon. Oen \& Wu [6] and Sylvester \& Cashel [7] developed an assay in which RNA polymerase catalyzes a template-dependent single step addition of a single nucleotide substrate to a short length primer such as a dinucleoside monophosphate. By this method the authors demonstrated that the single step addition of ATP to ApU directed by the poly[d(A-T)] template results in forma-

*Correspondence to: Marek Radlowski 
tion of a stable transcription complex bearing a stoichiometric amount of ApUpA. In contrast, the single step addition of UTP to UpA proceeds until UTP substrate exhaustion and therefore results in catalytic production of UpApU.

Here we report that 2-mercaptoethanol and dithiothreitol cause a marked enhancement of the UpA primed UpApU synthesis catalyzed by $E$. coli RNA polymerase on poly [d(A-T)] as template. We also report that 5,5'-dithio-bis(2nitrobenzoic) acid behaves as a very potent inhibitor of the single step addition reaction. In contrast, the effect of these reagents on the rate of productive elongation was very limited.

\section{MATERIALS AND METHODS}

Reagents. Nucleoside triphosphates and the dinucleoside monophosphate UpA were from Sigma. $\left[\alpha-{ }^{32}\right.$ P]UTP $(410 \mathrm{Ci} / \mathrm{mmol})$ was from Amersham. Poly[d(A-T)] was from Pharmacia.

Enzyme. E. coli RNA polymerase holoenzyme was a generous gift from Manfreid Schnaar (CNRS, Strasbourg, France). The enzyme solution $(1.7 \mathrm{mg} / \mathrm{ml})$ was diluted at least 1000 -fold in the transcription assays. Since the enzyme storage buffer contained $0.1 \mathrm{mM}$ dithiothreitol, concentration of the remaining reductant in the assays was less than $0.1 \mu \mathrm{M}$.

Reaction assays. Under standard conditions, reaction mixtures leading to labeled $\mathrm{UpApU}$ synthesis contained $17.2 \mu \mathrm{M}$ poly[d(A-T)] (in base pairs units), $0.9 \mathrm{mM} \mathrm{UpA}, 3 \mathrm{nM}$ enzyme, $1 \mu \mathrm{M}\left[\alpha-{ }^{32} \mathrm{P}\right] \mathrm{UTP}$ and $10 \mathrm{mM} \mathrm{MgCl}_{2}$, in a solution composed of $64 \mathrm{mM}$ Tris/HCl, $\mathrm{pH} 7.8$, $12.5 \%(\mathrm{v} / \mathrm{v})$ glycerol, $0.05 \mathrm{mM}$ EDTA and 1.5 $\mathrm{mM}$ NaF. Apparent $K_{\mathrm{m}}$ and $V_{\mathrm{m}}$ values were calculated from linear least square analysis of the resulting Lineweaver-Burk plots. When poly[d(A-T)] was varied, UpA was at $0.9 \mathrm{mM}$ and UTP at $1 \mu \mathrm{M}$. When UpA was varied, UTP was at $1 \mu \mathrm{M}$ and poly[d(A-T)] at $17.2 \mu \mathrm{M}$ (base pairs units). When UTP was varied, UpA was at $0.9 \mathrm{mM}$ and poly[d(A-T)] at $17.2 \mu \mathrm{M}$ (base pairs units). In parallel experiments the assays also contained $100 \mu \mathrm{M}$ ATP, thus leading to the synthesis of labeled poly[r(A-U)] chains. Assay mixtures containing all components, except triphosphate substrate(s), were preincubated for $15 \mathrm{~min}$ at $35^{\circ} \mathrm{C}$ (final volume $8 \mu \mathrm{l}$ ) in the absence or presence of various concentrations of 2 -mer- captoethanol, dithiothreitol or 5,5'-dithio-bis(2nitrobenzoic) acid, prior to incubation for 45 min at $35^{\circ} \mathrm{C}$. Similar results were obtained when the preincubation was conducted for up to $2 \mathrm{~h}$. Reactions were initiated by addition of 2 $\mu \mathrm{l}$ substrate solutions. They were stopped by adding $10 \mu \mathrm{l}$ stop solution containing $1 \mathrm{mM}$ EDTA and $80 \%$ formamide. UpApU synthesis was followed by thin-layer chromatography on poly(ethyleneimine)-cellulose sheets of $4 \mu \mathrm{l}$ volumes (reaction mixtures + stop solution) with $0.1 \mathrm{M} \mathrm{LiCl} / 1 \mathrm{M} \mathrm{HCOOH}$ as the solvent system [8]. Under these conditions the nonused triphosphate substrate remained bound at the origin, and UpApU migrated with an $R_{\mathrm{f}}$ of 0.41 . Following radioautography, all radioactive spots were cut out and counted in a liquid scintillation counter. Poly[r(A-U)] synthesis was quantified by trichloroacetic acid precipitation of reaction mixtures spotted on Whatman GF/C filters [9].

\section{RESULTS}

In agreement with previous reports $[6,7]$, we observed that $E$. coli RNA polymerase holoenzyme catalyzed very efficiently condensation of UTP substrate to UpA primer to form the trinucleoside diphosphate UpApU in the presence of poly[d(A-T)] as template. The reaction was strictly dependent on the presence of enzyme, DNA template, metal ion cofactor and primer. Figure 1(a) shows that the rate of UpApU synthesis was much greater in the presence of dithiothreitol or 2-mercaptoethanol. Half maximal activation occurred for reagent concentrations in the range of $0.1-0.3 \mathrm{mM}$. In contrast, the rate of poly[r(A-U)] synthesis was not affected by the presence of either of the two reducing agents.

The mechanism of activation was assessed by determination of apparent $K_{\mathrm{m}}$ and $V_{\mathrm{m}}$ values associated with formation of UpApU (Table 1). Reactions were carried out in the presence and absence of $1 \mathrm{mM}$ 2-mercaptoethanol. When UTP was varied substrate the effect of 2-mercaptoethanol was greater than that inferred from the results in Fig. 1(a), mainly because the apparent $K_{\mathrm{m}}$ for UTP was higher in the presence of the reductant than in its absence. At saturating UTP concentration, the rate of UpApU synthesis was increased 5-fold in the 

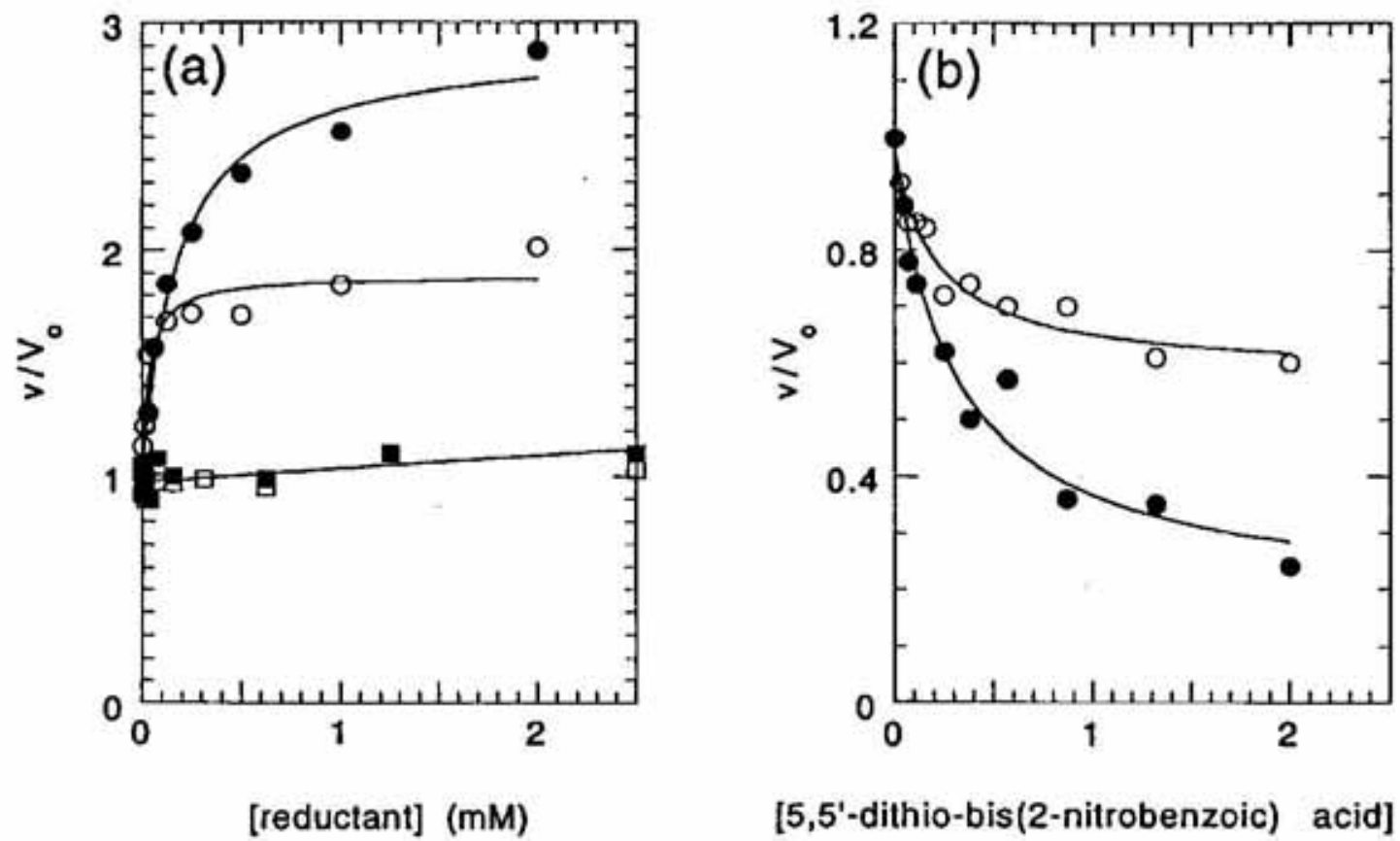

[5,5'-dithio-bis(2-nitrobenzoic) acid] (mM)

Fig. 1. Influence of reducing agents and of 5,5'-dithio-bis(2-nitrobenzoic) acid concentration on the rates of UpApU and poly[r(A-U)] syntheses catalyzed by E. coli RNA polymerase.

Reactions leading to UpApU synthesis were performed as described under Materials and Methods in the presence of 3 $\mathrm{nM}(0.03 \mathrm{pmol}) E$. coli RNA polymerase holoenzyme, $10 \mathrm{mM} \mathrm{MgCl}, 1 \mu \mathrm{M}\left[\alpha{ }^{32} \mathrm{P}\right] U T \mathrm{TP}, 17.2 \mu \mathrm{M}$ poly[d(A-T)], $0.9 \mathrm{mM}$ UpA, and varying concentrations of 2-mercaptoethanol, dithiothreitol or 5,5'-dithio-bis (2-nitrobenzoic) acid. In parallel experiments the assays containing also $100 \mu \mathrm{M}$ ATP, thus leading to the synthesis of labeled poly[r(A-U)] chains. Rate values were expressed as amount of UMP incorporated into UpApU or poly[r(A-U)] product for the $10-\mu l$ reaction mixtures during the 45 -min incubations at $35^{\circ} \mathrm{C}$. Rate measurements, $v$, were normalized to the corresponding values, $V_{0}$, obtained in the absence of reagent: $V_{0}=1.5$ pmol UMP incorporated for UPApU synthesis; $V_{0}=2.2$ pmol UMP incorporated for poly[r(A-U)] synthesis. (a) Reducing agents. Effect of 2-mercaptoethanol $(\mathrm{O})$ and dithiothreitol $(\bullet)$ on

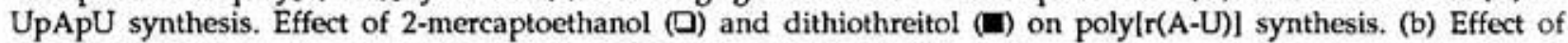
5,5'-dithio-bis(2-nitrobenzoic) acid on UpApU $(\bullet)$ and poly[r(A-U)] $(\mathrm{O})$ syntheses.

presence of $1 \mathrm{mM} 2$-mercaptoethanol (Table 1). The $K_{\mathrm{m}}$ values for template and primer were nearly equivalent under both conditions. From these data it is clear that the amount of UpApU synthesized was much greater than that of enzyme, implying that the single step addition reaction proceeded catalytically and that the reaction product was released in the bulk solution. Kinetic parameters associated with UpApU formation were nearly identical with those previously determined by Sylvester \& Cashel [7] for $E$. coli RNA polymerase holoenzyme under similar experimental conditions (Table 1).

The effect of the sulfhydryl reagent 5,5'-dithio-bis(2-nitrobenzoic) acid on the rates of abortive and productive elongation is shown in Fig. 1(b). The increase in the reagent concentration up to $2.5 \mathrm{mM}$ was associated with a marked impediment of UpApU synthesis and with a moderate inhibition of poly[r(A-U)] synthesis. The apparent kinetic parameters associated with formation of $\mathrm{UpApU}$ in the presence

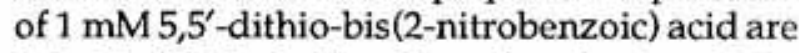
listed in Table 1 . The $K_{\mathrm{m}}$ values for template, UpA primer and UTP substrate were nearly equivalent for the 5,5'-dithio-bis(2-nitrobenzoic) acid containing assays compared to those calculated from the corresponding assays carried out in the absence of the sulfhydryl reagent (Table 1).

\section{DISCUSSION}

The fact that omission of a disulfide reagent from the transcription buffer does not significantly affect the rate of template-directed poly- 
Table 1

Steady state kinetic parameters associated with the UpA primed synthesis of UpApU

Reactions leading to UpApU synthesis were performed as described under Materials and Methods in the presence of 3 $\mathrm{nM}(0.03$ pmol $) E$. coli RNA polymerase holoenzyme, $10 \mathrm{mM} \mathrm{MgCl}_{2}$ and varying concentrations of $\left[\alpha{ }^{32} \mathrm{P}\right] \mathrm{UTP}$ substrate, poly[d(A-T)] template and UpA primer. Rate values were expressed as amount of UpAPU synthesized in the 10- $\mu 1$ reaction mixtures during $45 \mathrm{~min}$ incubations at $35^{\circ} \mathrm{C}$.

\begin{tabular}{|c|c|c|c|c|}
\hline \multirow[b]{2}{*}{ Conditions } & \multicolumn{3}{|c|}{$K_{m}$ values associated with UpApU formation for } & \multirow{2}{*}{$\begin{array}{c}V_{\mathrm{m}} \\
\text { (pmol) }\end{array}$} \\
\hline & $\begin{array}{c}\text { poly[d(A-T)] } \\
(\mu \mathrm{M})\end{array}$ & $\begin{array}{c}\text { UpA } \\
(\mathrm{mM})\end{array}$ & $\begin{array}{l}\text { UTP } \\
(\mu \mathrm{M})\end{array}$ & \\
\hline Standard & $0.17 \pm 0.04$ & $0.32 \pm 0.06$ & $1.5 \pm 0.2$ & $3.6 \pm 0.4$ \\
\hline $1 \mathrm{mM}$ 2-mercaptoethanol & $0.15 \pm 0.01$ & $0.19 \pm 0.03$ & $4.5 \pm 1.0$ & $19.0 \pm 5.0$ \\
\hline $1 \mathrm{mM} \mathrm{DTN}^{1}$ & $0.10 \pm 0.01$ & $0.33 \pm 0.11$ & $2.2 \pm 0.4$ & $0.6 \pm 0.1$ \\
\hline E. coli holoenzyme ${ }^{2}$ & & 0.15 & 5.0 & \\
\hline E. coli core enzyme ${ }^{2}$ & & 1 & 66 & \\
\hline
\end{tabular}

${ }^{1} 5,5^{\prime}$-dithio-bis(2-nitrobenzoic) acid.

${ }^{2}$ For comparison are also included the data of Sylvester \& Cashel [7] for the poly [d(A-T)]-directed, UpA-primed synthesis of UpApU catalyzed by $E$. coll $\mathrm{RNA}$ polymerase holoenzyme or core enzyme. Conditions, $10 \mathrm{mM} \mathrm{MgCl}, 1 \mathrm{mM}$ 2-mercaptoethanol and 43.1 $\mu \mathrm{M}$ poly[d(A-T)].

merization of RNA chains by prokaryotic RNA polymerases is well documented $[10,11]$. In agreement with this finding Fig. 1(a) shows that neither 2-mercaptoethanol nor dithiothreitol affected the rate of poly[r(A-U)] synthesis. Also, in agreement with previous results [10], treatment of the enzyme with $5,5^{\prime}$-dithio-bis(2nitrobenzoic) acid resulted in a moderate loss by about $35 \%$, of the initial activity of poly[r(AU)] synthesis.

In contrast, the rate of UpApU synthesis was markedly enhanced in the presence of disulfide and sulfhydryl reagents. Thus, in the presence of $1 \mathrm{mM}$ 2-mercaptoethanol there was a 5-fold increase in the rate of UpApU synthesis. The data in Table 1 show that this effect was not associated with changes in the number of transcription complexes or in utilization of dinucleotide primer and UTP substrate. They suggest that 2-mercaptoethanol mainly affected the rate of UpApU release and therefore the stability of the ternary transcription complexes enzyme-

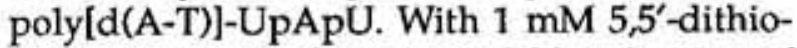
bis(2-nitrobenzoic) acid a 6-fold reduction of the rate of UpApU synthesis was obtained. As for 2-mercaptoethanol, the data in Table 1 support the notion that this effect was not due to modifications of DNA, primer and/or nucleotide substrate utilization by the enzyme, but reflected, most probably, a change in the stability of the ternary transcription complexes engaged in formation of a single phosphodiester bond.

Most of the previously reported studies have documented the effect of the sequence and conformation of the DNA template on the rate and extent of abortive elongation catalyzed by RNA polymerase $[6-8,12-15]$. The present study illustrates the possibility that modifications in the enzyme itself may also alter the stability of ternary transcription complexes involved in formation of the first phosphodiester bond in RNA synthesis.

\section{REFERENCES}

1. von Hippel, P.H., Bear, D.G., Morgan, W.D. \& McSwiggen, J.A. (1984) Protein-nucleic acid interactions in transcription: A molecular analysis. Annu. Rev. Biochem. 53, 389-446.

2. Carpousis, A.J. \& Gralla, J.D. (1980) Cycling of ribonucleic acid polymerase to produce oligonucleotides during initiation in vitro at the lac UV5 promoter. Biochemistry 19, 3245-3253.

3. McClure, W.R., Cech, L. \& Johnston, D.E. (1976) A steady state assay for the RNA polymerase initiation reaction. J. Biol. Chem. 253, 8941-8948.

4. Gralla, J.D., Carpousis, A.J. \& Stefano, J.E. (1980) Productive and abortive initiation of transcription in vitro at the lac UV5 promoter. Biochemistry 19, 5864-5869 
5. Munson, L.M. \& Reznikoff, W.S. (1981) Abortive initiation and long ribonucleic acid synthesis. Biochemistry 20, 2081-2085.

6. Oen, H. \& Wu, C.W. (1978) DNA-dependent single-step addition reaction catalyzed by Escherichia coli RNA polymerase. Proc. Natl. Acad. Sci. U.S.A. 75, 1778-1782.

7. Sylvester, J.E. \& Cashel, M. (1980) Stable RNA-DNA-RNA polymerase complexes can accompany formation of a single phosphodiester bond. Biochemistry 19, 1069-1074.

8. Dietrich, J., Teissere, M., Job, C. \& Job, D. (1985) Poly[d(A-T)] dependent trinucleotide synthesis catalysed by wheat germ RNA polymerase II. Effects of nucleotide substrates and cordycepin triphosphate. Nucleic Acids Res. 13, 6155-6170.

9. Job, D., Durand, R., Job, C. \& Teissere, M. (1984) Complex RNA chain elongation kinetics by wheat germ RNA polymerase II. Nucleic Acids Res. 12, 3303-3319.

10. Nicholson, B.H. \& King, A.M.Q. (1973) Thiol function and tertiary structure of RNA polymerase of Escherichia coli. Eur. J. Biochem. 37, 575-584.

11. Krakow, J.S. (1975) On the role of sulfhydryl groups in the structure and function of the Azotobacter vinelandii RNA. Biochemistry 14, 4522-4527.

12. Job, D., Job, C., de Mercoyrol, L. \& Shire, D. (1991) Transcription of synthetic DNA containing sequences with dyad symmetry by wheat-germ RNA polymerase II. Eur. J. Biochem. 195, 831-839.

13. Job, D., Marmillot, P., Job, C. \& Jovin, T.M. (1988) Transcription of left-handed Z-DNA templates: Increased rate of single-step addition reaction catalyzed by wheat germ RNA polymerase II. Biochemistry 27, 6371-6378.

14. Corda, Y., Job, C., Anin, M.-F., Leng, M. \& Job, D. (1991) Transcription by eucaryotic and procaryotic RNA polymerase of DNA modified at a d(GG) or a d(AG) site by the antitumor drug cis-diamminedichloroplatinum (II). Biochemistry 30, 222-230.

15. Corda, Y., Anin, M.-F., Leng, M. \& Job, D. (1992) RNA polymerases react differently at $d(A p G)$ and $\mathrm{d}(\mathrm{GpG})$ adducts in DNA modified by cis-diamminedichloroplatinum (II). Biochemistry 31, 1904-1908. 